\title{
recildunds
}

Revista Cientifica Mundo de la Investigación y el Conocimiento

Nadia Jesús López Álvarez a ; Ingrid Jacqueline Ronquillo Loy ; Andrea Estefanía Vaca Pino ${ }^{\text {c; }}$ Diana Karina López Quiñonez ${ }^{d}$

Biopsia ganglio centinela en cáncer de mama

Sentinel node biopsy in breast cancer

Revista Científica Mundo de la Investigación y el Conocimiento. Vol. 3 núm. 4., diciembre, ISSN: 2588-073X, 2019, pp. 279-295

DOI: $10.26820 /$ recimundo/3.(4).diciembre.2019.279-295

URL: http://recimundo.com/index.php/es/article/view/663

Código UNESCO: 3205 Medicina Interna

Tipo de Investigación: Artículo de Revisión

(C) RECIMUNDO; Editorial Saberes del Conocimiento, 2019

Recibido: 15/09/2019

Aceptado: 23/11/2019

Publicado: 30/12/2019

Correspondencia: nadiaj_28@hotmail.com

a. Médico; Investigador Independiente; Guayaquil, Ecuador; nadiaj_28@hotmail.com

b. Médico; Investigador Independiente; Guayaquil, Ecuador; ingridjr104@ hotmail.com

c. Médico; Investigador Independiente; Guayaquil, Ecuador; andreavaca1802@ hotmail.com

d. Médico; Investigador Independiente; Guayaquil, Ecuador; kary08d05@ outlook.com 


\section{Biopsia ganglio centinela en cáncer de mama}

Vol. 3, núm. 4., (2019)

Nadia Jesús López Álvarez; Ingrid Jacqueline Ronquillo Loy; Andrea Estefanía Vaca Pino; Diana Karina López Quiñonez

\section{RESUMEN}

El ganglio centinela se define como el primer ganglio que recibe el drenaje directamente desde el tumor primario. Si éste es negativo en el estudio anatomopatológico, puede evitarse una linfadenectomía innecesaria. La biopsia de ganglio linfático centinela puede ayudar a algunos pacientes a evitar cirugías más extensas de los ganglios linfáticos. La extirpación de más ganglios linfáticos cercanos, con el fin de buscar células cancerosas, quizás no sea necesaria si el ganglio centinela presenta resultados negativos de cáncer. La confirmación de metástasis en ganglio centinela axilares implica la linfadenectomía reglada axilar, con laterapia adyuvante posterior (quimioterapia, radioterapia y/u hormonoterapia) que se indique en función de las características de tumor primario, el tipo de cirugía realizada (conservadora o radical) y el análisis definitivo del material de linfadenectomía. La biopsia selectiva del ganglio centinela es la técnica más adecuada en la estadificación del cáncer de mama, permite localizar y biopsiar el primer ganglio de drenaje de la mama y así predecir el estado exacto de los ganglios en un alto porcentaje de los casos. El cáncer de mama se inicia usualmente en los conductos mamarios. Se sospecha que la mayoría de los carcinomas ductales se inician en una forma no invasiva que se denomina carcinoma intraductal. El cáncer invasivo o infiltrante de mama puede extenderse localmente dentro de la mama, puede llegar a infiltrar la piel o los músculos pectorales y puede también extenderse por los conductos linfáticos a los ganglios de la axila. El cáncer de mama puede invadir los vasos sanguíneos locales y emitir células metastásicas que pueden emigrar a órganos distantes (hueso, pleura, pulmón, hígado) dando lugar a metástasis a distancia. La metodología usada es descriptiva, con un enfoque documental, es decir, revisar fuentes disponibles en la red, como google académico, con contenido oportuno y relevante desde el punto de vista científico y actualizado que enriquezca el análisis del tema planteado en este artículo.

Palabras Claves: Ganglio Centinela; Biopsia; Extirpación; Linfadenectomía; Ganglio Linfático; Estadificación del Cáncer; Metástasis; Tumor Primario. 


\title{
Biopsia ganglio centinela en cáncer de mama
}

Vol. 3, núm. 4., (2019)

Nadia Jesús López Álvarez; Ingrid Jacqueline Ronquillo Loy; Andrea Estefanía Vaca Pino;

Diana Karina López Quiñonez

\begin{abstract}
The sentinel node is defined as the first node to receive drainage directly from the primary tumor. If this is negative in the pathology study, unnecessary lymphadenectomy can be avoided. Sentinel lymph node biopsy can help some patients avoid more extensive lymph node surgeries. The removal of more nearby lymph nodes, in order to look for cancer cells, may not be necessary if the sentinel node has negative cancer results. Confirmation of axillary sentinel node metastases involves axillary regulated lymphadenectomy, with subsequent adjuvant laterapy (chemotherapy, radiotherapy and / or hormonal therapy) that is indicated based on the characteristics of the primary tumor, the type of surgery performed (conservative or radical) and the definitive analysis of lymphadenectomy material. The sentinel node selective biopsy is the most appropriate technique in staging breast cancer, it allows to locate and biopsy the first drainage node of the breast and thus predict the exact state of the ganglia in a high percentage of cases. Breast cancer usually begins in the breast ducts. It is suspected that most ductal carcinomas begin in a noninvasive form called intraductal carcinoma. Invasive or infiltrating breast cancer can spread locally within the breast, can infiltrate the skin or pectoral muscles and can also spread through the lymph ducts to the axillary ganglia. Breast cancer can invade local blood vessels and emit metastatic cells that can migrate to distant organs (bone, pleura, lung, liver) leading to distant metastases. The methodology used is descriptive, with a documentary approach that is, reviewing sources available on the web, such as google scholar, with timely and relevant content from the scientific and updated point of view that enriches the analysis of the topic raised in this article.
\end{abstract}

Keywords: Sentinel Node; Biopsy; Excision; Lymphadenectomy; Lymph Node; Cancer Staging; Metastasis; Primary Tumor. 


\section{Biopsia ganglio centinela en cáncer de mama}

Vol. 3, núm. 4., (2019)

Nadia Jesús López Álvarez; Ingrid Jacqueline Ronquillo Loy; Andrea Estefanía Vaca Pino; Diana Karina López Quiñonez

\section{Introducción.}

La técnica del ganglio centinela es un procedimiento usado en estadios tempranos de cáncer de mama el cual es seguro y poco mórbido comparándolo con el vaciamiento axilar, que permite predecir el estado de compromiso ganglionar axilar de manera segura y precisa con falsos negativos de 8,4\% (Aristizabal-Quintero, Marzo 2015). El centinela no es un ganglio único, sino el que esté más próximo a la zona del tumor y muestre las primeras señales de que algo no va bien.

La biopsia de ganglio linfático centinela, por lo general, se usa para ayudar a determinar el estadio del cáncer de seno y del melanoma. Sin embargo, ese procedimiento se está evaluando con otros tipos de cánceres, como el cáncer colorrectal, el cáncer gástrico, el cáncer de esófago, el cáncer de cabeza y cuello, el cáncer de tiroides y el cáncer de pulmón de células no pequeñas. Por eso, las campañas de prevención del cáncer de seno se centran en la búsqueda de bultos o protuberancias, que indican la presencia de un tumor. Lo siguiente es determinar si se puede convertir en un cáncer y propagarse por el resto del cuerpo.

El ganglio centinela es el primer ganglio de una cadena linfática que drena la zona donde hay un tumor. Toda la linfa que proviene de esta zona debe pasar primero por este ganglio antes de proseguir el camino hacia el resto de ganglios, por lo tanto es el que tiene las probabilidades más altas de sufrir una metástasis inicial. Detectar si hay células tumorales en este ganglio será clave a la hora de evitar que se extienda la enfermedad. Si el resultado de este ganglio centinela es negativo se puede evitar el vaciado de los ganglios. 


\section{Biopsia ganglio centinela en cáncer de mama}

Vol. 3, núm. 4., (2019)

Nadia Jesús López Álvarez; Ingrid Jacqueline Ronquillo Loy; Andrea Estefanía Vaca Pino;

Diana Karina López Quiñonez

\section{Metodología.}

Esta investigación está dirigida al estudio del "Biopsia ganglio centinela en ganglio de mama”. Para realizarlo se usó una metodología tipo descriptiva, con un enfoque documental, es decir, revisar fuentes disponibles en la red, como google académico, con contenido oportuno y relevante desde el punto de vista científico para dar respuesta a lo tratado en el presente artículo y que sirvan de inspiración para realizar otros proyectos. Las mismas pueden ser consultadas al final, en la bibliografía.

\section{Resultados.}

El ganglio centinela se define como el primer ganglio que recibe el drenaje directamente desde el tumor primario. Si éste es negativo en el estudio anatomopatológico, puede evitarse una linfadenectomía innecesaria. Desde el punto de vista de la Medicina Nuclear, es aquel o aquellos que presentan una captación del trazador en la línea de progresión linfática desde el ganglio centinela, habitualmente con menor actividad, claramente diferenciada. Desde el punto de vista quirúrgico, es aquel o aquellos identificados o no previamente en la linfogammagrafía, que tienen una actividad significativamente menor en la misma área de drenaje del ganglio centinela (Goñi, 2009).

\section{Método.}

Linfografía radioisotópica para detectar ganglio centinela mediante gamma cámara (Noblía, 2004): 


\section{Biopsia ganglio centinela en cáncer de mama}

Vol. 3, núm. 4., (2019)

Nadia Jesús López Álvarez; Ingrid Jacqueline Ronquillo Loy; Andrea Estefanía Vaca Pino; Diana Karina López Quiñonez

1. Entre 18 y 24 horas previas a la cirugía se inyecta en la zona peritumoral un habón de 1 cm de coloide de albúmina marcado con 3500 microcurios de Tc 99 y se aplican masajes suavemente en el sitio de inyección.

2. Se procede a adquirir las respectivas imágenes. C Linfografía dinámica son 60 imágenes sucesivas de 15 segundos de duración cada una, que permiten evidenciar el canalículo aferente al ganglio centinela. La C Linfografía estática realizada a los 30 minutos, 1 hora y 2 horas. Si en este tiempo no se observó imagen ganglionar se prolonga el estudio.

3. Finalizada la linfografía dinámica se marca en la piel de la paciente la proyección de la ubicación del ganglio centinela.

4. Colocando marcas externas y realizando la cuantificación de la distancia, mediante un programa de la computadora de la gamma cámara, se logra medir la ubicación en profundidad del ganglio centinela.

5. De esta manera se indica al cirujano dónde se ubica el ganglio centinela y a qué profundidad se encuentra.

6. La actividad inyectada a la paciente es suficiente como para permitir al día siguiente la detección intraquirúrgica del ganglio centinela mediante un equipo portátil.

Técnica quirúrgica (Noblía, 2004)

1. Detección de la ubicación del ganglio centinela en forma transcutánea con el gamma probe. 


\section{Biopsia ganglio centinela en cáncer de mama}

Vol. 3, núm. 4., (2019)

Nadia Jesús López Álvarez; Ingrid Jacqueline Ronquillo Loy; Andrea Estefanía Vaca Pino;

Diana Karina López Quiñonez

2. Durante la disección axilar el cirujano encontrará con la sonda el o los ganglios linfáticos que contengan radiactividad.

3. Si hay dos o más ganglios radiactivos, deben ser extirpados.

4. Luego se coloca la sonda en el lecho axilar para verificar la ausencia de radiactividad.

5. En la primera etapa realizamos el vaciamiento axilar en todas las pacientes. En la segunda etapa, luego de lograr un valor de predicción del 95\%, si el ganglio centinela es negativo no realizamos el vaciamiento axilar.

Técnica para detectar el ganglio centinela con azul patente (Gallegos, 2004)

1. Inyección de $3 \mathrm{ml}$ de azul patente a $1 \%$ peritumoral (Roffo I, II y III). Si la paciente presenta una biopsia previa la inyección del colorante la realizamos pericicatrizal intraparenquimatosa. En el protocolo Roffo IV la inyección del colorante la realizamos subareolar.

2. Masaje manual de la zona coloreada durante 5 minutos.

3. Tumorectomía y biopsia por congelación.

4. A los 10 minutos de la inyección del colorante, realizamos una incisión axilar acorde a la técnica quirúrgica programada.

5. Disecamos la grasa axilar hasta encontrar un vaso linfático teñido o un ganglio impregnado con el colorante. 


\section{Biopsia ganglio centinela en cáncer de mama}

Vol. 3, núm. 4., (2019)

Nadia Jesús López Álvarez; Ingrid Jacqueline Ronquillo Loy; Andrea Estefanía Vaca Pino; Diana Karina López Quiñonez

6. Extraemos el ganglio y realizamos la biopsia por congelación del mismo. Estudio anatomopatológico.

En quirófano

1. Si el ganglio centinela es menor de $5 \mathrm{~mm}$ se congela sin seccionarlo; si es mayor de 5 mm se realiza hemisección del ganglio y congelación en criostato de una de sus mitades.

2. En el primer período de nuestro estudio se coloreaban 4 ó 5 cortes con azul de toluidina de una sola mitad del ganglio centinela, luego comenzamos a realizar 7 cortes de cada mitad del ganglio.

3. Se observa al microscopio y se emite el primer informe.

4. Se fijan en formol al $10 \%$ ambas mitades para el estudio diferido.

En laboratorio

1. Se incluyen ambas mitades en parafina y se realizan cortes de rutina coloreados con hematoxilina-eosina.

2. Si el ganglio centinela no muestra metástasis se procede a investigar micrometástasis con nuevos cortes que se colorean con hematoxilina-eosina y con técnica de inmunohistoquímica. Se utiliza la técnica biotina-estreptavidina con antígeno epitelial de membrana y/o citoqueratina. 


\section{Biopsia ganglio centinela en cáncer de mama}

Vol. 3, núm. 4., (2019)

Nadia Jesús López Álvarez; Ingrid Jacqueline Ronquillo Loy; Andrea Estefanía Vaca Pino; Diana Karina López Quiñonez

Beneficios de la Biopsia de ganglio de centinela

Colabora con los médicos a determinar el estadio del cáncer y a calcular el riesgo de que las células del tumor hayan adquirido la capacidad para diseminarse a otras partes del cuerpo, la biopsia de ganglio linfático centinela puede ayudar a algunos pacientes a evitar cirugías más extensas de los ganglios linfáticos. La extirpación de más ganglios linfáticos cercanos, con el fin de buscar células cancerosas, quizás no sea necesaria si el ganglio centinela presenta resultados negativos de cáncer. Toda cirugía de ganglios linfáticos puede causar efectos adversos, y algunos de esos efectos se pueden reducir o evitar si se extirpan menos ganglios.

La biopsia del ganglio linfático centinela, como otros procedimientos quirúrgicos, puede causar dolor por un tiempo, hinchazón y moretones en el sitio de la cirugía y aumentar el riesgo de infección. Además, algunos pacientes pueden presentar reacciones cutáneas o alérgicas al tinte azul usado en ese procedimiento. Otro posible perjuicio es un resultado negativo falso de la biopsia, es decir, no se ven células cancerosas en el ganglio linfático centinela aunque sí están presentes y pueden haberse diseminado ya a otros ganglios linfáticos de la región o a otras partes del cuerpo. Un resultado negativo falso da al paciente y al médico una falsa sensación de seguridad acerca de la extensión del cáncer en el cuerpo del paciente.

Protocolo a seguir en caso de ganglio centinela positivo

- La confirmación de metástasis en ganglio centinela axilares implica la linfadenectomía reglada axilar, con laterapia adyuvante posterior (quimioterapia, radioterapia $\mathrm{y} / \mathrm{u}$ hormonoterapia) que se indique en función de las características de tumor primario, el 


\section{Biopsia ganglio centinela en cáncer de mama}

Vol. 3, núm. 4., (2019)

Nadia Jesús López Álvarez; Ingrid Jacqueline Ronquillo Loy; Andrea Estefanía Vaca Pino; Diana Karina López Quiñonez

tipo de cirugía realizada (conservadora o radical) y el análisis definitivo del material de linfadenectomía.

- La confirmación de micrometástasis en el/los ganglio(s) centinela(s) axilar(es) implica igualmente la linfadenectomía, salvo en aquellos casos que se considere que pueden ser incluidos en ensayos clínicos específicos para el estudio de esta circunstancia.

- La aplicación de terapias adyuvantes (quimioterapia, radioterapia y/u hormonoterapia) vendrá dictada, fundamentalmente, por las características tumorales y del tipo de cirugía realizada (conservadora o radical) y del resultado de la linfadenectomía en el caso de llevarse a cabo. No existe evidencia suficiente para el tratamiento sistémico de las pacientes con micrometástasis.

- Ante la afectación de ganglio centinela de la mamaria interna y no afectación de ganglio centinela axilar, se recomienda tratamiento adyuvante de la cadena mamaria interna (radioterapia), sin completar la linfadenectomía axilar. Ante la afectación del ganglio centinela de la mamaria interna (en estudio diferido), sin haber drenaje axilar, se recomienda la posibilidad de seguimiento clínico y con técnicas de imagen, sin cirugía axilar.

- La existencia de células tumorales aisladas no implica la realización de ningún gesto añadido.

Biopsia selectiva de ganglio centinela (BSGC)

La biopsia selectiva del ganglio centinela es la técnica más adecuada en la estadificación del cáncer de mama, permite localizar y biopsiar el primer ganglio de drenaje de la mama y así 


\section{Biopsia ganglio centinela en cáncer de mama}

Vol. 3, núm. 4., (2019)

Nadia Jesús López Álvarez; Ingrid Jacqueline Ronquillo Loy; Andrea Estefanía Vaca Pino;

Diana Karina López Quiñonez

predecir el estado exacto de los ganglios en un 98 por ciento de los casos (Piñero, 2007). Además, es una técnica válida para evitar la linfadenectomía axilar. La linfadenectomía sirve para la estadificación de los tumores, como factor pronóstico, y en algunos casos como indicador de tratamiento, pero presenta una morbilidad muy importante. Hasta en un 80 por ciento de los casos se producen disestesias y parestesias y, además, seroma, linfedema crónico, neuropatías, infecciones y hombro congelado. Si se añade el tratamiento con radioterapia se multiplica por 2,4 la posibilidad de linfedema.

\section{Criterios de indicación}

- La realización de una biopsia escisional previa no contraindica la práctica de la BSGC siempre que se realice antes de un mes.

- Es aceptable, además, antes de un tratamiento sistémico primario con fines de rescate para cirugía conservadora.

- Por otra parte, no existe evidencia para recomendar la BSGC en mujeres gestantes ni en los casos de cirugía mamaria plástica de aumento o reducción previa. En pacientes con cirugía conservadora con BSGC previa por carcinoma no hay evidencia para recomendar una nueva biopsia.

- El futuro del cáncer de mama pasa por la utilización de las nuevas gammacámaras híbridas Spect-TAC, que localizan mejor el ganglio centinela, y nos dan una situación espacial más correcta y precisa que la gammagrafía normal. 


\section{Biopsia ganglio centinela en cáncer de mama}

Vol. 3, núm. 4., (2019)

Nadia Jesús López Álvarez; Ingrid Jacqueline Ronquillo Loy; Andrea Estefanía Vaca Pino; Diana Karina López Quiñonez

Todos los esfuerzos por determinar la situación de infiltración de los ganglios busca como objetivo último evitar la linfadenectomía axilar. La resección de los ganglios axilares produce gran morbilidad, con pérdida de fuerza en la extremidad, Linfedema, pérdida de sensibilidad y problemas de cicatrización entre otros.

\section{Linfadenectomía Axilar}

Es la extirpación de todos los ganglios linfáticos de la axila. Esto da una información muy precisa del estado de todos los ganglios linfáticos de la axila, para conocer si están invadidos por las células tumorales. Además de proporcionar información sobre el pronóstico, la linfadenectomía axilar continúa siendo el método más eficaz para controlar la enfermedad regional. En la actualidad se sigue realizando cuando el ganglio centinela es positivo y cumple ciertos criterios de riesgo. Después de la cirugía de los ganglios linfáticos, es posible que se presente dolor, sangrado, hinchazón, coágulos sanguíneos e infecciones.

Efectos secundarios de la Linfadenectomía Axilar (Cordobá, 2004):

\section{Linfedema}

Un posible efecto secundario a largo plazo de una cirugía de ganglios linfáticos es la hinchazón en el brazo o el pecho, llamado linfedema. Cualquier exceso de líquido en los brazos normalmente regresa al torrente sanguíneo a través del sistema linfático, la extirpación de los ganglios linfáticos algunas veces bloquea el drenaje del brazo, lo que causa la acumulación de este líquido. 


\section{Biopsia ganglio centinela en cáncer de mama}

Vol. 3, núm. 4., (2019)

Nadia Jesús López Álvarez; Ingrid Jacqueline Ronquillo Loy; Andrea Estefanía Vaca Pino; Diana Karina López Quiñonez

El linfedema es menos común después de una biopsia del ganglio linfático centinela que de una disección de ganglios linfáticos axilares. Se cree que el riesgo está entre 5\% a 17\% en las mujeres que se someten a una biopsia de ganglio linfático centinela y alrededor de $20 \%$ a $30 \%$ en las mujeres que se someten a una disección de ganglios linfáticos axilares (American Cáncer Society, 2018). Puede ser más común si la radiación se administra después de la cirugía o en mujeres que están obesas. Algunas veces se presenta una hinchazón que dura sólo unas pocas semanas y luego desaparece.

Movimiento limitado del brazo y del hombro

Es posible que también tenga limitaciones en el movimiento del brazo y el hombro después de la cirugía. Esto es más común después de una disección de ganglios linfáticos axilares que después de una biopsia del ganglio linfático centinela. Puede que su médico le aconseje hacer ejercicios para ayudar a evitar que presente problemas permanentes (un hombro congelado). Algunas mujeres notan una estructura parecida a una cuerda que comienza debajo del brazo y se puede extender hasta el codo, lo que a veces se conoce como adherencia cicatrizal o cordones linfáticos. Esto es más común después de una disección de ganglios linfáticos axilares que de una biopsia del ganglio linfático centinela. Puede causar dolor y limitar el movimiento del brazo y hombro. A menudo, este problema desaparece sin necesidad de tratamiento, aunque algunas mujeres podrían beneficiarse de la terapia física. 


\section{Biopsia ganglio centinela en cáncer de mama}

Vol. 3, núm. 4., (2019)

Nadia Jesús López Álvarez; Ingrid Jacqueline Ronquillo Loy; Andrea Estefanía Vaca Pino; Diana Karina López Quiñonez

\section{Entumecimiento}

El entumecimiento de la piel en la porción superior interna del brazo es un efecto secundario común, ya que los nervios que controlan esta sensibilidad en este lugar pasan a través del área de los ganglios linfáticos.

\section{Evolución del cáncer de mama}

El cáncer de mama se inicia usualmente en los conductos mamarios (y por ello se denomina carcinoma ductal), aunque un $10 \%$ se inicia en los lóbulos mamarios (y se denomina entonces carcinoma lobulillar) (Benet, 2010). Se sospecha que la mayoría de los carcinomas ductales se inician en una forma no invasiva (y por tanto, no grave en sí misma) que se denomina carcinoma intraductal. Este carcinoma intraductal (que debería cambiar su nombre para evitar alarmas innecesarias) no puede extenderse a distancia dando metástasis y por tanto se cura siempre por resección local. Sin embargo, si no se trata, algunos carcinomas intraductales pueden transformarse con el tiempo en cáncer invasivo, originando un verdadero cáncer de mama. El cáncer invasivo o infiltrante de mama puede extenderse localmente dentro de la mama, puede llegar a infiltrar la piel o los músculos pectorales y puede también extenderse por los conductos linfáticos a los ganglios de la axila (más raramente a los de la cadena ganglionar mamaria interna). Finalmente, el cáncer de mama puede invadir los vasos sanguíneos locales y emitir células metastásicas que pueden emigrar a órganos distantes (hueso, pleura, pulmón, hígado) dando lugar a metástasis a distancia. De acuerdo con los niveles de extensión, la UICC clasifica el cáncer de mama en 4 estadios (Martín, Junio 2015):

- Estadio I: tumores pequeños, sin afectación metastática de la axila. 


\section{Biopsia ganglio centinela en cáncer de mama}

Vol. 3, núm. 4., (2019)

Nadia Jesús López Álvarez; Ingrid Jacqueline Ronquillo Loy; Andrea Estefanía Vaca Pino;

Diana Karina López Quiñonez

- Estadio II: tumores de más de $2 \mathrm{~cm}$ o con afectación metastática de la axila moderada.

- Estadio III: tumores muy grandes o con afectación de piel o músculo pectoral o afectación axilar masiva.

- Estadio IV: metástasis en órganos distantes (hueso, pulmón, hígado...).

El pronóstico de estos estadios es muy diferente, con supervivencias aproximadas a 5 años con $95 \%$ (estadio I), $80 \%$ (estadio II), $60 \%$ (estadio III) y $25 \%$ (estadio IV).

\section{Conclusión.}

Los ganglios linfáticos son partes importantes del sistema inmunitario del cuerpo. Si detectan una sustancia extraña, algunas de sus células se activan, lo cual inicia una respuesta inmunitaria. La respuesta del ganglio centinela ha permitido actualizar algunas técnicas de los médicos para abordar la enfermedad. Antes se hacía un vaciamiento de la región linfática de la axila, que le quitaba movilidad a esta zona del cuerpo, pero en los últimos años se comenzó a utilizar lo que denominamos la detección del ganglio centinela que está más cerca de la zona donde se sospecha hay un tumor, evitando procedimiento dolorosos e innecesarios.

En una biopsia de ganglio linfático centinela o en cirugías más extensas de los ganglios linfáticos, se cortan los vasos linfáticos que llegan al ganglio centinela o salen de él o de un grupo de ganglios, por lo que se altera el flujo normal de linfa en la zona afectada. La alteración puede resultar en una acumulación anormal de linfa. Además de la hinchazón, los pacientes con linfedema pueden sentir dolor o molestia en la zona afectada, y el tejido cutáneo que cubre esa zona puede hacerse grueso o duro. Si se hace cirugía extensa de ganglios linfáticos en la axila o en la ingle, la hinchazón puede afectar todo el brazo o toda la 


\section{Biopsia ganglio centinela en cáncer de mama}

Vol. 3, núm. 4., (2019)

Nadia Jesús López Álvarez; Ingrid Jacqueline Ronquillo Loy; Andrea Estefanía Vaca Pino; Diana Karina López Quiñonez

pierna. Además, hay un riesgo mayor de infección en la zona o extremidad afectada. Muy rara vez, el linfedema crónico que resulta de la extirpación extensa de los ganglios linfáticos puede llevar a un tipo de cáncer de vasos linfáticos llamado linfangiosarcoma.

La biopsia del ganglio linfático centinela, como otros procedimientos quirúrgicos, puede causar dolor por un tiempo, hinchazón y moretones en el sitio de la cirugía y aumentar el riesgo de infección. Además, algunos pacientes pueden presentar reacciones cutáneas o alérgicas al tinte azul usado en ese procedimiento. Otro posible perjuicio es un resultado negativo falso de la biopsia, es decir, no se ven células cancerosas en el ganglio linfático centinela aunque sí están presentes y pueden haberse diseminado ya a otros ganglios linfáticos de la región o a otras partes del cuerpo

Estos resultados justifican la importancia de mejorar la prevención, el tratamiento y el manejo del linfedema, que es actualmente una de las principales complicaciones del tratamiento del cáncer de mama debido a su cronicidad y a su impacto en la calidad de vida. Hoy en día, gracias al programa de cribado del cáncer de mama, la mayoría de los casos son detectados en estadios iniciales que pueden ser intervenidos quirúrgicamente con la técnica del ganglio centinela, evitando así complicaciones en el brazo y consiguiendo una mejor recuperación y calidad de vida de las enfermas.

\section{Bibliografía.}

American Cáncer Society. (2018). Cirugía de ganglios linfáticos para el cáncer de seno. Obtenido de American Cáncer Society: https://www.cancer.org/es 


\section{Biopsia ganglio centinela en cáncer de mama}

Vol. 3, núm. 4., (2019)

Nadia Jesús López Álvarez; Ingrid Jacqueline Ronquillo Loy; Andrea Estefanía Vaca Pino; Diana Karina López Quiñonez

Aristizabal-Quintero. (Marzo 2015). Biopsia de ganglio centinela en cáncer de mama después de neoadyuvancia en una población latinoamericana. Revista Colombiana de Cancerología, 19(1), 3 - 9.

Benet, L. (2010). Actualización del consenso sobre la biopsia selectiva del ganglio centinela en el cáncer de mama. Revista de senología y patología mamaria, 23(5), 1 - 7.

Cordobá, A. (2004). Ganglio centinela en cáncer de mama. Estudio histológico de 67 casos. Anales del Sistema Sanitario de Navarra, 27(2).

Gallegos, J. (2004). Mapeo linfático y biopsia del ganglio centinela en pacientes con cáncer de mama. Cirugía y Cirujanos, 72(5), 357 - 360.

Goñi, E. (2009). Ganglio centinela en cáncer de mama: biopsia selectiva comparada con linfadenectomía axilar. Seguimiento a largo plazo. Anales Sistema Sanitario de Navarra, 32(3).

Martín, M. (Junio 2015). El Cáncer de Mama. ARBOR Ciencia, Pensamiento y Cultura, 15(1), 1 $-7$.

Noblía, C. (2004). Ganglio centinela en cáncer de mama actualización de resultados de protocolos de investigación del instituto de oncología. Revista argentina de mastología, $242-256$.

Piñero, A. (2007). Reunión de consenso sobre la biopsia selectiva del ganglio centinela en el cáncer de mama. Sociedad Española de Senología y Patología Mamaria. REVISTA ESPAÑOLA DE PATOLOGÍA, 42(1).

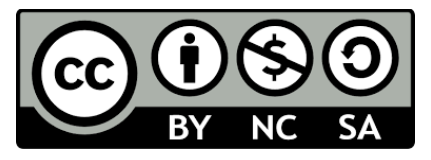

RECONOCIMIENTO-NOCOMERCIAL-COMPARTIRIGUAL

CC BY-NC-SA

ESTA LICENCIA PERMITE A OTROS ENTREMEZCLAR, AJUSTAR Y CONSTRUIR A PARTIR DE SU OBRA CON FINES NO COMERCIALES, SIEMPRE Y CUANDO LE RECONOZCAN LA AUTORÍA Y SUS NUEVAS CREACIONES ESTÉN BAJO UNA LICENCIA CON LOS MISMOS TÉRMINOS. 